doi.rg/ 10.51891/rease.v7ir2.3486

\title{
A INFLUÊNCIA DA INTERNET NA ESCRITA
}

\author{
Antonio José Ferreira Gomes ${ }^{1}$
}

RESUMO: A escrita está na humanidade há milhares de anos. Ela cumpre o papel de comunicar, de interagir e de registros dos conhecimentos, ações e intenções humanas. Com o passar dos tempos, ela ganhou estruturas e normas que dentro de muitas ciências faz com que a exigência da língua obedece a coerência e a padronização dela como ciência. Entretanto, há de se observar que dentro de uma escrita, existem diversos gêneros como as orientações de um manual, bula de remédio e também o gênero digital ou como dizem da internetês. Cada gênero desse cumpre uma função distinta. $\mathrm{O}$ seu uso obedece a um lugar e uma exigência específica. Ninguém escreve uma carta para um amigo usando uma linguagem culta, clássica e altamente elaborada como também não deveria fazer em um vestibular o uso de uma escrita que está presente nas mídias sociais. Por isso, escola devem levar alunos a compreender essa questão, para que não sejam postos em uma escrita na escola, que não atenderia a norma padrão brasileira. Para entender todo esse contexto, a pesquisa utilizou a metodologia bibliográfica e o método qualitativo, que apresentaram diversos resultados. A escola deve perceber o gênero da linguagem digital como um mecanismo de reflexão entre os alunos, mas não a coibir, pois os alunos não entenderiam o porquê de não a utilizar, mas devem ser levados a compreender o que é escrita, formas de escrita e quando usar um tipo ou outro em determinada situação.

Palavras-chave: Escrita. Internet. Reflexão.

ABSTRACT: Writing has been in humanity for thousands of years. It fulfills the role of communicating, interacting and recording human knowledge, actions and intentions. Over time, it gained structures and norms that within many sciences make the requirement of language obey its coherence and standardization as a science. However, it should be noted that within a writing, there are several genres such as the guidelines of a manual, medicine leaflet and also the digital genre or as they say in Internetese. Each such genre fulfills a distinct function. Its use obeys a specific place and requirement. Nobody writes a letter to a friend using a cultured, classical and highly elaborated language, nor should they use a script that is present

\footnotetext{
${ }^{I}$ Pós-Graduado em Pedagogia Digital pela Faculdade UniBF (2021); Pós-Graduado em Docência da Educação a Distância pela Faculdade UniBF (202I); Pós- Graduado em Docência do Ensino Superior pela Faculdade Metropolitana São Carlos (2020); Possui a Formação Pedagógica Rzem Pedagogia pela Faculdade UniBF (202I) e o Curso Superior em Tecnologia em Segurança Pública pela Universidade Estácio de Sá (2017). Atualmente é Policial Militar na Polícia Militar do Estado do Rio de Janeiro. E Instrutor no Centro de Formação e Aperfeiçoamento de Praças- CFAP/PMERJ.
} 
in social media in an entrance exam. Therefore, schools must lead students to understand this issue, so that they are not put into writing at school, which would not meet the standard Brazilian standard. To understand this entire context, the research used the bibliographic methodology and the qualitative method, which presented different results. The school must perceive the digital language genre as a mechanism for reflection among students, but not to curb it, as students would not understand why not to use it, but they must be led to understand what writing is, forms of writing and when to use one type or another in a given situation.

Keywords: Writing. Internet. Reflection.

\section{INTRODUÇÃO}

A escrita está presente na humanidade há muito tempo. Especialistas apontam que ela já fazia parte de uma sociedade há mais de 4000 anos a.C. Com o passar dos anos, ela foi ganhando estruturas e um campo de regras e normas dentro de diversas ciências. Esses campos além de normatizar a língua faz a compreensão de como meios existentes na sociedade podem afetar não somente a comunicação, mas a própria escrita.

Um exemplo disso está no advento da internet. Quando ela se fez presente na vida das pessoas entre as décadas de 1990 e 2000 e fez com que as pessoas tivessem um importante instrumento para se comunicar. $O$ modelo empregado nesse novo mundo digital é a rapidez. E isso afetou inclusive a escrita. No meio digital muitas trocas de mensagens não obedecem a ortografia e a gramática, tão necessárias e percebidas pela escola. $O$ internetês é um novo gênero textual que deve também ser percebido pelas instituições de ensino.

Para entender essas questões, o artigo levanta a seguinte problemática: De como a escrita foi influenciada pela internet e de como a escola estuda esse fenômeno?

A hipótese pode entender que a internet dá um acesso maior a leitura, pois livros, revistas e uma infinidade de coisas, estão presentes nela, porém isso não é capaz de fazer com seus usuários escrevam melhor, muito pelo contrário, agem no sentido da rapidez. Por isso, fragmentam palavras ou até mesmo as substituem por determinados símbolos.

Trazer esse texto para a estudo, justifica pela necessidade de compreender os efeitos da internet no modo de escrita das pessoas. Embora ela possua pontos 
positivos como na pesquisa e acesso a leitura de muitos livros, possui um campo aberto para um novo fenômeno escrito que a escola ainda não absorve como certo. Cabe a ela, entender esse novo campo da escrita e levar ao aluno também compreender que ela só deve ser utilizada no meio digital e não nos textos que exigem a norma mais padronizada.

Toda a pesquisa construída nesse trabalho, obedece a metodologia bibliográfica e ao método qualitativo. Em relação a pesquisa do tipo bibliográfico Sousa et. al. (2021) entende que ela está muito presente em trabalhos acadêmicos e pretende atualizar conhecimentos através de uma busca científica. Essa pesquisa científica pode ser realizada em consulta a livros, revistas, periódicos e outros documentos que sirvam se base para as fases de escrita. Em relação ao método qualitativo Bardin fala que a análise do conteúdo se constrói em três etapas: a pré análise, a exploração do material e tratamento dos resultados obtidos e interpretação. $\mathrm{Na}$ verdade, esses três elementos fazem parte do método qualitativo que visa fazer uma análise mais apurada do material lido para posterior reescrita, com percurso interpretativo fidedigno ao objeto científico encontrado em algum documento.

De acordo com Bardin (2011, p. 47).

[...] um conjunto de técnicas de análise das comunicações visando a obter, por procedimentos sistemáticos e objetivos de descrição do conteúdo das mensagens, indicadores (quantitativos ou não) que permitam a inferência de conhecimentos relativos às condições de produção/recepção (variáveis inferidas) destas mensagens (Bardin, 20II, p. 47).

As fontes de pesquisa foram consultas em grande parte no meio digital com o uso de internet e ferramentas de busca como Google Livros e Scielo. Deu-se prioridade para publicações dos últimos dez anos. Através dos descritores: escrita, internet e reflexão possibilitou o encontro de diversos autores sobre a temática, sendo que 23 foram compostos na parte bibliográfica da pesquisa.

Estruturalmente o trabalho está dividido em duas seções. Na primeira seção aborda-se a temática sobre o surgimento da internet no Mundo e no Brasil, as suas funcionalidades e de começou a fazer parte na vida das pessoas. $\mathrm{Na}$ segunda seção, fala-se de como a internet tem influenciado a escrita, de modo que regras de 
ortografia e gramatical, tão preservadas pela norma padrão, estão sendo esquecidas e isso tem prejudicado a própria língua.

\section{SURGIMENTO DA INTERNET}

Os meios de comunicação sempre foram considerados uma importante arma para ações estratégicas de países em conflitos, principalmente pelo Estados Unidos e a União Soviética. Eram dois países altamente em conflitos pela disputa de poder comercial e no fortalecimento de ideologias durante o período da Guerra Fria. Por isso, cada país começou a desenvolver melhor as tecnologias existentes para ter mais efetividades em suas ações militares (AZEVEDO, 200I).

A internet nasceria justamente pela engenharia militar no ano de 1969 nos Estados Unidos. Inicialmente a internet receberia o nome de ARPA (Advanced Reserach Projects Agency), que foi um produto que poderia ser um meio de comunicação eficiente no período da Guerra Fria para criar centros de defesa contra a União Soviética (AZEVEDO, 20or).

Para Azevedo (200I, p. oI)

A própria internet é fruto da engenharia militar. Nascida nos Estados Unidos em 1969, seu nome original era ARPA (Advanced Research Projects Agency). Produto da guerra fria, que dividia o mundo entre duas potências, Estados Unidos e União Soviética, a função da internet era militar, para articular centros de defesa em caso de um ataque soviético. Hoje, a internet encontra-se na sua terceira fase, a comercial. (AZEVEDO, 20or, p. or).

Nas perspectivas de Lins (2013) a rede de internet foi um resultado de um esforço de defesa norte americana contra possíveis ataques soviéticos. que poderiam atacar os Estados Unidos com armamento nuclear. Por isso, ela surge como um canal comunicativo efetivo para que pudesse subsidiar os americanos com informações mais rápidas em lugares estratégicos.

Para Lins (2013) depois disso a internet revolucionaria o mundo, mas ela passou por quatro fases importantes. A primeira foi o uso privado das redes. As redes nesse momento eram realizadas por conexões entre computadores de grande porte. As conexões eram feitas por cabeamento com o uso das linhas telefônicas, mas se permitia a transferência de documentos 24 horas por dia. 
O segundo momento, descrito por Lins (2013) foi quando por meio de rede discada a internet começou a ser discada por meio de um provedor de acesso. Já se tinha a inclusão dos hipertextos, de sítios e páginas, ainda em forma somente de texto, que poderiam ser acessadas através do hiperlink. No terceiro momento, nasce com o surgimento da banda larga, que permitia um acesso mais rápido, os conteúdos já tinham imagem e áudio, e o surgimento das redes de entretenimento como o Orkut.

Por fim, Lins (2013) surge o smartphone. A internet passou a fazer parte da rotina e trabalhos das pessoas de forma muito maior. Amplia-se as redes sociais, surge a computação em nuvem, a tv digital e tudo o que conhecemos hoje através de muitos aparelhos eletrônicos com acesso à internet.

Os primeiros momentos da internet surgiram em 1958 pelo departamento de defesa do Estados Unidos para usar como arma militar. No ano de 1962, surge a ARPANET, que foi criada por um grupo de universitários e militares através de um programa chamado Information Processing Techiniques. O objetivo da Aparnet já consistia em estimular a pesquisa através dos computadores (CASTELLS, 2003).

Castells (2003) aponta que no ano de 1969 os primeiros centros de pesquisa da Universidade da Califórnia se conectaram a ARPANET. No ano de i971 esses centros já contabilizavam is nós. Com a possiblidade de otimizar tempo e fazer pesquisas rápidas, os grande e pesados computadores deram lugar aos PC.

De acordo com Côrrea (2013, p. 19)

\begin{abstract}
A conexão em rede promovida pela Arpanet trazia outro benefício de grande importância: a otimização do tempo de utilização dos computadores da época. Os computadores da década de 196o eram enormes, pesados e extremamente caros, custando entre cinco e dez milhões de dólares em valores atualizados. Os computadores pessoais, conhecidos como PCs que conhecemos hoje é um estágio avançado destes computadores que eram chamados de "computadores de tempo compartilhado". (CÔRREA, 2013, p. 19).
\end{abstract}

O que está implícito na citação acima, é de que com o avanço das tecnologias ao longo dos anos, o acesso e o barateamento delas se tornou algo possível. Isso seria mais tarde um grande negócio não somente para vincular com maior efetividade a comunicação, mas sim trazer o acesso à tecnologia para milhões de pessoas.

Para Vaz (s.d) até os anos de 1980 a internet era uma ferramenta de pesquisa para poucos. Já no ano de 1980 a 1990 a internet se expandiu para grande parte da 
sociedade mundial de forma exponencial. Mais computadores foram colocados no comércio e a internet deixaria de fazer parte de uso somente militar para também ser acessado pelos civis. Na transição dos anos de 1970 a 1980 foi fundamental a mudança de padrão de conexão, que deram permissão aos protocolos da internet nascerem entre eles estão o TCP/IP.

De acordo com Barros (2016) em 1983 a rede de computadores entre uma grande extensão baseada em TCP/IP. Desse modo todos os compudores que usavam a ARPANET migraram para a nova tecnologia. Já em 1985 nasceria a Narional Science Fundation Network, que tinha um conjunto de 56 redes de universidades interconectadas em 56 kilobits por segundo.

Já em uma ordem mais contemporânea, a internet que já vinha sendo usada para alguns ramos de negócio, vou um percurso importante para assegurar empregos, negócios, estudos e pesquisas devido ao período da Pandemia trazida pelo novo coronavírus. Isso fez com que as pessoas utilizassem diversos recursos através de modernos aparelhos eletrônicos, que até então eram usados somente para uso de redes sociais (ALVES, et. al, 2020).

Segundo Alves et. al, (2020) as pessoas usaram a internet para suprir a presencialidade física das pessoas, uma vez que em tempos de isolamento as conversas, os diálogos mais próximos foram limitados ou até mesmo proibidos, com isso a palavra desconectar ficou difícil de ser usada, as pessoas passam horas e horas em frente uma tela fazendo negócios, trabalhando e se divertindo.

Segundo Macedo (2017) os primeiros passos da internet no Brasil foram na década de 1980, especificamente no ano de 198I, por da BITNET, que era uma rede de universidades fundadas no ano de 198I que se interligava a Universidade da cidade de Nova Yourk e a Fundação de Amparo à Pesquisa de São Paulo, por meio de um cabo submarino.

No ano de 1994 a internet sai da Fundação e começa a ser comercializada pela Embratel em caráter experimental e com conexão internacional de $256 \mathrm{kbps}$. Nessa fase experimental cinco mil usuários foram escolhidos para testar o serviço. Em 1995 por meio do Ministério das Telecomunicações a internet é comercializada em todo o país e fez cada vez mais parte da vida das pessoas. 
No Brasil existe um Comitê Gestor da Internet que tem a funções justamente de regulamentar e observar todas as políticas de uso da internet e a oferta de serviços pelo setor público ou privado. Esse comitê gestor foi criado pela Portaria Interministerial n. ${ }^{\mathrm{a}}$ I47 de $3 \mathrm{I}$ de maio de 1995, que teve a regulamentação de atividades pelo Decreto 4829 de 03 de setembro de 2003. Já a Lei 12.965/2014 traz como função a regulamentação do Marco Civil da Internet. (COMITÊ GESTOR INTERNET NO BRASIL, 2014).

E é pela Lei 12.965/2014 que o comitê gestor, de observância e criação das diretrizes do uso da internet no Brasil, estabelece que todo o tratamento aos pacotes de dados de posse dos sistemas autônomos sem que sobre ele recaia degradação do conteúdo, bem como discriminação, origem, destino e aplicação serão tratados de forma isonômica, de trato igual, sem ter uma decisão unilateral para a concretização dos serviços e dos fluxos de navegação pela rede de internet. (COMITÊ GESTOR DA INTERNET, 2014, p. o2).

Conforme o Comitê Gestor da Internet (2014) a regulamentação que versa a lei 12965/2014 apresenta regras na proteção de registros aos dados pessoais de todos os usuários em suas comunicações troca de dados privados e também à guarda de registro de conexões e de acesso a internet. Isso porque com o Marco Civil da Internet a legislação protege com mais eficiência os usuários nos mais diversos interesses sobre ela.

Segundo o Senado Federal (2013) o Comitê Gestor da Intenet no Brasil, assume as seguintes demandas: realizar a gestão do registro de domínio usando o [br], dispondo desse modo de endereços IPs e ASNs; realizar debates e programas que promovam sempre a qualidade da internet no país; propor programas de P\&D que promovam a disseminação e o uso da internet de forma legal e em observância às leis do país, ser consoante com a implantação de diretrizes de uso, registro e propriedade da internet com aqueles já dirimidos pela cúpula da internet internacional.

\section{A INFLUÊNCIA DA INTERNET NA ESCRITA}

Diniz (2020) esclarece que o perfil de leitores no Brasil pertence em maior parte as classes A e B. As mulheres leem mais do que homens. Os pré adolescentes 
de II a 13 anos são o grupo de leitores que mais tem contato com um livro. Ao longo do avanço das idades, o tempo de leitura diminui. muitas pessoas justificam que não possuem tempo para ler. O Brasil é um país que promove poucas ações de leitura. Isso é prejudicial pelo fato de que quanto menos se lê, menos conhece o mundo a sua volta e menos crítico e reflexivo uma pessoa pode ser tornar-se.

Com o surgimento da internet o acesso a leitura ficou mais fácil para todas as faixas sociais e etárias. Pois o mundo digital oferta um mundo gigantesco de leitura. Porém, esse mesmo mundo da leitura digital, tão acessível, muitas vezes, são acessados apenas para cumprir um requisito educacional (MUNARI, 20II).

Ribas (2005) esclarece que a internet pode oferecer um mundo amplo de acesso a leitura, mas ela se tornou sinônimo de rapidez e agilidade, por isso, devido ao mundo com menos tempo para ler ou escrever, as pessoas tem uma escrita diferente no meio digital, que é absorvida quando de posse ou necessidade da escrita convencional.

Apontado por Carmo et. al, (2016) o meio digital implicou em uma mudança de rotina na vida das pessoas. A pressa e a rapidez com que as coisas devem ser geradas fazem nascer um novo gênero de escrita, que nem sempre obedece a uma norma padrão. Isso faz nascer um conflito entre aluno e professor.

Araújo (2017) considera que o uso de uma escrita na internet faz parte de dois campos importantes de análise. O primeiro é o uso de uma nova linguagem, suprimida e usual no mundo da internet. $O$ segundo seria de como em meios de um ensino conservador poderia absorver como fonte de estudo essa nova prática de escrita, sem que sobre ela sejam realizados preconceitos e não observação da escola por ela.

A internet faz com que a escrita fuja das normas padronizadas da língua portuguesa. $O$ maior problema é quando na hora da exigência da escrita mais elaborada, como numa redação, o aluno transfere as palavras com letras suprimidas ou por códigos para o texto escrito. Segundo Couldry (2005) quando a internetês faz presente em uma situação mais padronizada da língua, pode ela enfraquecer o próprio idioma ou estudo dele, mas esse tipo de gênero de ser entendido e trabalhado em sala de aula, para que os alunos possam usar a linguagem da internetês somente nas conversas menos formais. 
Segundo Melo e Santana (2017)

É, pois, importante destacar que o internetês é uma linguagem muito utilizada nos dias de hoje, porém o seu uso deve ser atrelado ao contexto virtual, não interferindo nos escritos convencionais. Por conta disso, não devem ser considerados erros de grafia quando este tipo de escrita está ligado diretamente a determinados gêneros textuais no meio virtual. (MELO; SANTANA, 2017).

Melo e Santana (2017) acreditam que se deve deixar muito claro para alunos que o uso da linguagem no meio digital não pode ser usado na escrita convencional. Embora ela passe a mensagem que propõe a dizer, fere um conjunto de regras e normas da própria língua, que obedece a uma ciência, que é importante para a identidade dela como

$\mathrm{Na}$ concepção de Carmo (2016) a internet oferece vantagens e desvantagens. A vantagem estaria em troca de mensagens por uma escrita rápida, mas de forma muito negativa é que essa escrita no mundo digital influencia no dia a dia dos estudantes, até mesmo no nível de graduação. Isso faz pensar que a internet que deveria se um mundo vasto para enriquecer o conhecimento através de diversas leituras, traz as pessoas um certo comodismo na hora de escrever, que além de fazer a supressão de palavras, esquecem das regras que compõem a língua portuguesa.

De acordo com Carmo (2016, p. 04)

É cobrado sempre ao universitário o ato da reflexão sobre o que escrever ou falar, não é aceito que ao longo de um curso o jovem não saiba escrever ou refletir sobre as suas palavras a serem transpassadas para a caligrafia convencional. Deve haver a consciência de que além de nos fazermos entender, temos que pensar bem para sermos claros naquilo em que pretendemos transpassar, seja em qualquer sentido, falado ou escrito (CARMO, 2016, p. o4).

Rodrigues (2020) aponta que o mundo digital, nas comunicações rápidas e interativas não conseguem absorver uma linguagem clássica, padronizada. $O$ fato é que os interlocutores precisam rapidamente passar a informação, que ficaria truncada se o modelo de escrita fosse adotado em consonância com o modo culto da língua. Desse modo, cabe ao professor trazer essa linguagem do meio digital e fazer reflexões com seus alunos sobre ela. Afinal de contas, o uso abreviado da linguagem com poucas letras e o uso emotions é apenas um cumprimento do que a internet exige como rapidez. 
Rodrigues (2020) as palavras convergem para uma escrita suprimida na internet como aqui (aki), porque (pq) entre tantas outras. Ela passa a mensagem aos interlocutores, mas não obedecem a norma padrão. Em blog foi exposto uma imagem que coloca justamente como ocorre esse tipo de comunicação no meio digital, como demonstrado na Figura I.

Figura I - A Comunicação da Internetês

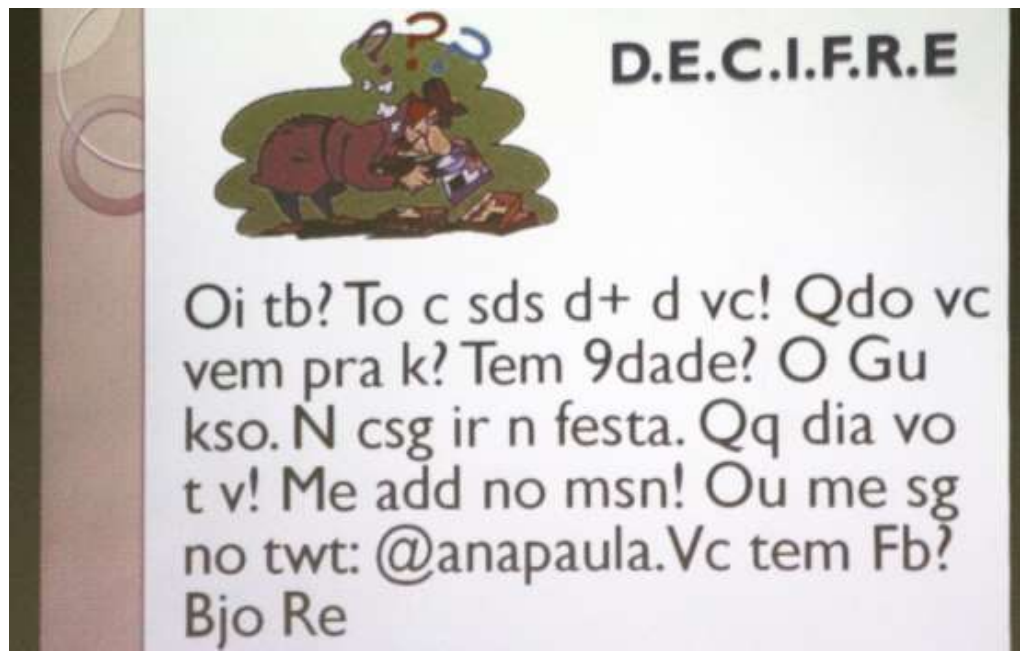

Fonte: Nascimento (2013)

Esse exemplo mostrado por Nascimento (2013) mostra que a mensagem abrevia toda a palavra, mas ainda atende a questão da pontuação. Entretanto, isso deve ser visto com cautela, uma vez que ao escrever constantemente abreviado na tela de um computador, faz o aluno esquecer como é a grafia corretas de determinadas palavras. Não se poderia, mesmo ainda em um ensino mais tradicional, fechar os olhos para esse novo tipo de linguagem no meio digital.

Monte Mór (2012) acredita que o ensino em todas as suas fases e modalidades ainda é composto por ações hermenêuticas tradicionais. Isso faz com que haja rupturas do próprio saber que sequer faz uma ligação transdisciplinar com outras áreas do conhecimento, sobretudo faz com que os alunos sejam levados a internalizar o conteúdo que lhes é dado sem entenderem ao certo sua função e uso no meio em que vivem. 
De forma muito clara, Janks (2010) esclarece que esse caminho de ensino voltado para um modelo tradicional e mecânico só potencializaria as desigualdades sociais entre os alunos. E que o momento trazido pelas inovações da própria globalização e da tecnologia exige mudanças nas estruturas do próprio ensino. Isso porque percebe-se que as instituições de ensino ainda criam certa resistência para os novos contextos surgidos na sociedade, que impactam no seu modo de se comportar, relacionar, buscar o conhecimento e letrar-se.

É importante que a escola repense seu ensino de forma a abrir espaço para um ensino letrado e crítico, moderno e aliado aos interesses da sociedade e tudo que se relaciona a ela, principalmente deve deixar de lado um ensino somente sobre o papel para dar aberturas para outras formas de um ensino letrado que podem vir do meio digital, pois ela está presente na vida dos sujeitos, que precisam aprender a lidar com esse novo gênero, para buscarem informação, formação e outros elementos de forma correta e crítica como é apontado por Castells (2006).

Moravec (20II) ressalta que além de possibilitar aos alunos um contato com novos gêneros textuais imprescindíveis para a formação, é preciso que as instituições de ensino deixem do ensino somente enraizado nas formas mecânicas e pouco efetivas para buscar também um ensino digital, que já tão presente na vida das pessoas, mas seu uso ainda é restrito nos espaços de ensino.

A escola quando fecha os seus olhos para o novo, gera ela própria o fracasso, segundo Freire (2009), que aponta que dissociada de uma ação conjunta na construção de conceitos, forma alunos que muitas vezes se enquadram em pessoas que dominaram o código escrito, mas não exercem autonomia sobre ele, muito pelo contrário, quando postos às práticas mais críticas do uso efetivo da língua, encontram barreiras.

\section{CONSIDERAÇÕES FINAIS}

A sociedade não vive sem a internet. Ela, que teve seu advento comercial no ano de 1990 entre os brasileiros, é hoje importante para o trabalho, estudo e lazer. Embora a sociedade utilize a internet para uma série de funções, não se poderia permitir que ela rompa com uma escrita já consolidada por uma norma padronizada. 
Isso porque a linguagem digital é um gênero textual, mas jamais poderia subsistir o modo com que se escreve há muito tempo.

Dito isso, é importante fazer uma grande reflexão sobre escrita e o uso da internet. Escolas não podem fechar os olhos para esse novo gênero. Devem levar os alunos a entender o uso dela e sua ineficiência para uma escrita mais elaborada, pois em exames para aprovação em concursos ou vestibulares, a escrita da internet seria altamente desconsiderada.

Se isso é tido como certo, o aluno deve também fazer uma reflexão do modo que opera sua escrita, pois deve perceber que no uso do dia-a-dia da internet como forma de interação apenas, pode fazer o uso da escrita com supressão de palavras, mas deve entender que a constituição da língua é posta por uma escrita coerente e com observância às suas regras pela norma padrão brasileira.

Portanto, cabe uma reflexão de tudo isso não somente pela escola, mas por alunos que precisam compreender que existem diversos gêneros como o literário, jurídico ou econômico que se fossem usados no dia a dia, tornariam a linguagem cansativa e inacessível a muitos falantes. Mas o seu uso obedece a momentos próprios, assim como na esfera digital, que usar palavras novas ou muitas delas diferentes das regras ortográficas não é proibido, mas não atenderia em um ambiente formal ou escolar.

\section{REFERENCIAS BIBLIOGRÁFICAS}

ALVES, A.E..de. ANDRADE G. da S; OLIVEIRA, J.A. O uso das Redes Sociais na Pandemia. IV Congresso Internacional de Gestão em Tecnologias. 2020. Disponível em https://cointer.institutoidv.org/smart/2020/pdvg/uploads/48o.pdf. Acesso em o6 de dezembro de 2021.

ARAÚJO, J. de M. S. A Influência dos Internetês na Escrita dos Alunos do Ensino Médio da Escola i9 de Julho. 2017. Disponível em https://s3-sa-eastI.amazonaws.com/sophiauta/Letras/TCC+on-line/Joelma.pdf. Acesso em o7 de dezembro de 2021.

AZEVEDO, C. Meios de Comunicação como armas de guerra. Texto da Biblioteca Online de Ciências da Comunicação. 200I. Disponível em http://www.recensio.ubi.pt/modelos/documentos/documento.php3?coddoc $=1042.07$ de dezembro de 2021. 
BARDIN, L. Análise de conteúdo. São Paulo: Edições 70. 201 .

CARMO, F.M. do; MACHADO, L.M; MENEZES, T. D. O. de. A Escrita Virtual e sua Interferência na Escrita Convencional. 20I6. Disponível em https://portal.fslf.edu.br/wp-content/uploads/2016/12/tcc_02-2.pdf. Acesso em o7 de dezembro de 202I.

CASTELLS, M. A galáxia da Internet: Reflexões sobre a internet, os negócios e a sociedade. Rio de Janeiro: Jorge Zahar Editor Ltda. 2003

CASTELLS, M. A sociedade em rede. 4 ed. São Paulo: Paz e Terra, 2000.

COMITÊ GESTOR DA INTERNET. Contribuição do Comitê Gestor da Internet no Brasil à Regulamentação da Lei 12.965/2014 - o Marco Civil da Internet. Disponível em https://www.cgi.br/media/docs/publicacoes/4/contribuicao-docomite-gestor-da-internet-no-brasil.pdf. Acesso em o7 de dezembro de 202I.

CORREA, F.S. Um estudo qualitativo sobre as representações utilizadas por professores e alunos para significar o uso da Internet. Dissertação de Mestrado, Universidade de São Paulo: Ribeirão Preto, 2013.

COUDRY, M. I. H. A linguística. Campinas Unicamp 2005.

DAVIS, G.J; LEE, T. Microsoft Windows Server 2003 TCP/IP Protocols and Services, Microsoft. Net, 2003.

DINIZ, T. Retratos da Leitura: Um país que lê menos. Itaú Social. Disponível em https://www.itaucultural.org.br/secoes/noticias/retratos-leitura-pais-le-menos.

Aceso em o7 de dezembro de 2021.

FISHER, S. O que significa TCP/IP?. 2019. Disponível em https://www.avast.com/pt-br/c-what-is-tcp-ip\#gref. Acesso em o7 de dezembro de 2021.

FREIRE, P. Carta de Paulo Freire aos Professores. ESTUDOS AVANÇADOS is (42), 20or. Disponível em Untitled-I4 (scielo.br). Acesso em I3 de abril de 2021.

JANKS, H. Literacy and power. London: Routledge, zoro.

LINS, B.F.E. A Evolução da Internet: Uma Perspectiva Histórica. Cadernos ASLEGIS | 48 . Janeiro/Abril. 2013 
MACEDO, H.RL.Surgimento e Evolução da Internet no Brasil. 2017. Disponível em https://www.eletronet.com/surgimento-e-evolucao-da-internet-no-brasil/. Acesso em o6 de dezembro de 2021.

MAESTRElli, M; TROVÃO, B; JANUZZI, F. Segurança na Web. Centro Brasileiro de Pesquisas Físicas, Rio de Janeiro, 2000.

MELO, E.A. de; SANTANA, F.P. A influência da linguagem da internet na escrita formal: uma pesquisa com alunos do $9^{\circ}$ ano na cidade de Tobias Barreto-Se. Revista Cadernos de Estudo e Pesquisa na Educação Básica. Recife. v. 3, n.I, 2017.

MONTE MÓR, W. A formação de professores e alunos na sociedade digital: políticas e práticas educacionais no ensino-aprendizagem de línguas estrangeiras. In: DALBEN, A. I. F. et al. (Org.). Convergências e tensões no campo da formação e do trabalho docente. Belo Horizonte: Autêntica, 2010. p. 577-594. (Coleção Didática e Prática de Ensino)

MUNARI, A.C. Literatura e Internet. Editora Pontifícia Universidade Católica do Rio Grande do Sul. 2oIr.

RIBAS, E; RIBAS, A; LAHN, R.A. A influência da linguagem virtual na linguagem formal de adolescentes. 2005. Disponível em http://www.cinted.ufrgs.br/ciclog/artigos/8dElisangela.pdf. Acesso em o7 de dezembro de 202I.

SENADO FEDERAL. O Modelo Brasileiro de Governança da Internet. 2013. Disponível em https://wwwi2.senado.leg.br/ecidadania/documentos/anexos/audiencia-cctgovernanca-da-internet-20-08-2013/o-modelo-brasileiro-de-governanca-da-internetcgi.br-hartmut-glaser. Acesso em o7 de dezembro de 202I.

SOUSA, A.S. de; OlIVEIRA, G.S.de; AlVES, L.H. Pesquisa Bibliográfica: Princípios e Fundamentos. Cadernos da Fucamp, v.20, n.43, p.64-83/202I

VAZ, P. Cronologia da Internet. Lugar Comum, n. 13, s.d. Disponível em https://uninomade.net/wp-

content/files_mf/II2410120232Cronologia\%20da\%2oInternet\%20\%20Paulo\%2oVaz.pdf. Acesso em o7 de dezembro de 2021. 